\title{
La agrupación guerrillera Granada- Málaga: estudio sobre las mentalidades y la vida cotidiana
}

\author{
José María Azuaga Rico
}

\section{INTRODUCCIÓN}

La agrupación guerrilera Granada-Málaga considerada por algunos como la más poderosa de las que actuó durante la postguerra española ${ }^{1}$, será analizada en este trabajo desde un enfoque distinto al que normalmente se utiliza para estudiar el movimiento guerrilero. No nos referiremos al desarrollo cronológico de la misma, a la relación de enfrentamientos que tuvo con la fuerza pública y al número de bajas producidas en los mismos, aspectos que han tratado las investigaciones realizadas hasta ahora en otras regiones y que corresponden más a una historia política, en sentido estricto, y militar. Nuestro enfoque, sin olvidar los aspectos políticos, será el de la historia de las mentalidades y de la vida cotidiana.

Para ello hemos recurrido, especialmente, a las fuentes orales, al testimonio hablado de las personas que estuvieron en la organización guerrillera y, también, en el campo contrario, en la Guardia Civil. Quizás ahí se encuentre uno de los aspectos originales de nuestro trabajo: salvo pocas excepciones, como la reciente obra de Fernanda Romeu sobre la Agrupación Guerrillera de Levante ${ }^{2}$, la historiografia reciente suele con-

- Asi opinaba Eulogio Limia en su "Reseña general del bandolerismo en España después de la Guerra de Liberación". ACCPCE. Movimiento guerrillero. Caja 1, carp. 3/2. pág. 25.

${ }^{2}$ La autora recoge el testimonio del guardia civil Ángel Martín Díaz-Quijada. Romeu Alfaro, F.: La Agrupación Guerrillera de Levante. Valencia, Ed. Alfons el Magnàmim, 1987. 
ceder la palabra al bando derrotado en aquel conflicto, guiada posiblemente del deseo de hacer contrahistoria y dar, por tanto, la voz a los vencidos. Constituye esto último una explicable reacción a la historiografía oficial del franquismo, que recurría, exclusivamente, a las fuentes procedentes del régimen. Sin embargo, esa reciente historiografía, no suele caer en el partidismo de su predecesora, pues sobre mostrarse crítica en la interpretación de los testimonios y en el análisis, tanto de la actuación guerrillera, como de la Guardia Civil.

En otro apartado se encuentra la historiografía que, también en la época de Franco, se generó desde el exilio, lógicamente limitada en la consulta de las fuentes, pero que suele caer en la hagiografia del movimiento guerrillero.

En este trabajo se observará que las coincidencias entre los testimonios orales de ambos bandos son, a veces, asombrosas, y dependen de la sinceridad de nuestros interlocutores. La utilidad de los mismos es palmaria a la hora de analizar aspectos como la vida cotidiana, comúnmente ignorados en las fuentes escritas. También la coincidencia entre las fuentes escritas y las orales aparecerá en muchos casos a lo largo de esta investigación aunque, en otros, se completan unas a otras o se contradicen.

Cuando la persona entrevistada ha deseado ocultar su nombre, lo sustituiremos por un pseudónimo, precedido de un asterisco.

Fundamentalmente hemos recurrido a tres archivos: el del Centro de Estudios Históricos de la Guardia Civil, el de la antigua Capitanía General de Granada y el del Comité Central del Partido Comunista de España, que no sólo contienen documentación propia sino también del bando opuesto.

En el archivo del Centro de Estudios Históricos de la Guardia Civil (CEHGC), el fondo mayor lo constituyen los expedientes de los guerrilleros, con antecedentes de los mismos, hechos que se les atribuyeron y las llamadas "Notas Informativas" referidas a enfrentamientos y al final que tuvieron esos guerrilleros. Para una historia factual este archivo es de importancia, siempre que su contenido se contraste con otros testimonios; en este trabajo nos ha sido especialmente útil a la hora de analizar el lenguaje empleado y las imágenes que, a través de él, se transmitían.

El archivo de la antigua Capitanía General de Granada (ACGG) contiene los procedimientos jurídicos llevados a cabo en caso de hecho delictivo (asesinato, secuestro, atraco...) y las causas contra los guerrilleros 
detenidos, con sus atestados, indagaciones, acusaciones del fiscal, alegaciones de la defensa y sentencias. Como en los fondos de la Guardia Civil analizaremos también el lenguaje empleado por las autoridades.

Se puede aplicar el contenido de este archivo el análisis que Georges Duby hace de la documentación empleada por Le Roy Ladurie en "Montaillou, una aldea occitana»: se oye en él, directamente, la voz de campesinos (en nuestro caso de los guerrilleros capturados), pero mediatizados ante un tribunal, con miedo al castigo y rodeados de enemigos. Esa voz aparece especialmente en los atestados que, tras la detención, les hace la Guardia Civil: la falta de abogado defensor, dada la inexistencia del derecho de habeas corpus, hace pensar, como señalan los supervivientes, en la atmósfera de presión en que se realizaron esas declaraciones.

Todo ello no invalida el valor de ese archivo: ante el juez suele haber rectificaciones de las declaraciones de los atestados, se aportan datos para la historia de los acontecimientos y se puede hacer un seguimiento de las investiaciones realizadas por las autoridades juridico-militares.

El lenguaje guerrillero puede analizarse en la documentación del Archivo del Comité Central del Partido Comunista de España (ACCPCE). A esta organización pertenecian los dirigentes y buena parte de las bases de la guerrilla granadino-malagueña. Contiene información de guerrilleros huidos al extranjero, prensa clandestina o editada en el exilio, consignas y normas enviadas a la sierra, así como documentación de las autoridades franquistas y, salvo alguna excepción que veremos, como el Informe de Miguel Salado Cecilia, no recoge la realidad del guerrillero, sus dificultades o los aspectos de su vida cotidiana.

En nuestro trabajo, comenzaremos viendo las causas de la guerrilla, especialmente la represión, que afectaría a las futuras bases guerrilleras y el móvil, puramente político, de sus dirigentes. Al estudiar estos últimos veremos el papel que, en el plano cultural, desempeñaron. Seguidamente analizaremos el debate terminológico que existe en torno a los términos "bandolerismo" y "guerrilla", lo que nos llevará al estudio del lenguaje empleado por los dos bandos enfrentados y a las imágenes que querian transmitir. Por último, veremos diferentes parcelas de la vida cotidiana del guerrillero: penalidades sufridas, papel de los enlaces, alimentación, economía guerrillera, alojamiento y sexualidad. Insertaremos, a lo largo del trabajo, documentación oral y escrita, que será analizada y que, creemos, ayudará a demostrar nuestras afirmaciones. 
CAUSAS Y CARACTERES DE LA GUERRILLA. EL PAPEL POLITICOCULTURAL DE LOS DIRIGENTES

Para comprender muchos de los aspectos que desarrollaremos en este trabajo, es necesario explicar los motivos por los que aquellas personas se integraron en la guerrilla.

A simple vista, fue la represión la causa principal de la lucha guerrillera, pero si profundizamos en el estudio de las fuentes, podremos observar el contexto de la misma y otros móviles que la acompañaron.

En efecto, la represión, característica fundamental del Régimen de Franco, y más intensa, en la guerra y en la postguerra, no dejó de afectar a gran parte de los futuros guerrilleros o a sus familiares. Cuando les hemos preguntado a los supervivientes por los motivos de su marcha a la sierra, la mayoría de ellos la dan como respuesta inmediata.

Normalmente, eran antiguos enlaces que temían ser detenidos, torturados o eliminados. El momento en que hubo mayor número de incorporaciones al maquis fue durante el mes de octubre de 1947, en el término municipal de Almuñécar (Granada); consultando los expedientes del Centro de Estudios Históricos de la Guardia Civil hemos contabilizado a 20 personas en esas circunstancias. La primera explicación a este hecho la obtendriamos de un guardia civil: uno de sus jefes, le dio la orden de presentarse en el cuartel de Almuñécar y, de la lista de desafectos al Régimen, conservada en el mismo, escoger a diez y fusilarlos. Quizás se pretendiera amedrentar a una zona en la que el maquis poseía un cierto arraigo. Nuestro interlocutor no deseaba cumplir esa orden y consiguió zafarse de ella, pero enviaron a otro oficial que sí la verificó, ejecutando finalmente a siete vecinos de Almuñécar, en el pueblo de Pinos del Valle (Granada) ${ }^{3}$.

En consecuencia, para evitar correr la misma suerte, aquellas personas, se incorporaron a la guerrilla.

${ }^{3}$ Entrevista con el guardia civil Fernando Planas. Julio de 1985 . Nota Informativa $n .{ }^{\circ}$ 331 de 20 de octubre de 1947. Origen: 136. ${ }^{a}$ Comandancia de la Guardia Civil (Granada). Destino: Segunda Sección de Estado Mayor (SIGC) Madrid (CEHGC). (Este documento habla de encuentro con muerte de siete "bandoleros").

Coinciden con la versión del guardia civil, los familiares de las victimas que hemos entrevistado en Almuñécar: todos señalan que los fallecidos fueron apresados en sus casas y, poco después, fusilados en Pinos del Valle. Dolores Trinidad, 23 de enero de 1988; Luis Olivares, 25 de febrero de 1988 y Carmen Díaz López, marzo de 1988). 
Algo similar había ocurrido, dos meses antes, en Los Tablones de Motril (Granada). Un tiroteo entre guerrilleros y guardias provocó la muerte de uno de éstos el 31 de julio de 1947. La represalia fue inmediata: 11 personas, entre ellas un guerrillero detenido, dos mujeres y un niño, fueron fusilados por la Guardia Civil al día siguiente. Huyendo de las ejecuciones, tres enlaces de la guerrilla marcharon a la sierra ${ }^{4}$.

Es frecuente oir en las zonas de actuación guerrillera, cuando se habla de un oficial especialmente represivo, que "echó a muchos a la sierra". Dos guardias civiles nos lo confirman.

“¿Quién tiene la culpa de que la gente se fuera a la sierra?... Aqui hubo tres hermanos, que eran tres comandantes de puesto y que echarían a la sierra al $50 \%$ de los hombres que han estado allim.

"Al tío que llevan al cuartel y le meten una paliza, a la tercera vez se va a la sierra: "a mi no me pegan"".

"Lo normal es que a consecuencia de una actuación desafortunada de la Guardia Civil huya la gente" 5 .

«El Cabo de Frigiliana era un criminal. Mató al yerno del Fraile "Paemonda" [Andrés Cuesta Ortega] y a varios (...) "Paemonda" era enlace de ellos (...) detuvieron a él y a tres más, y se los llevaron a un cuartel que había en Calaceite, y allí los tuvieron (...) y entonces, don Agustín le hizo la autopsia y me dijo: "a ése lo desfiguraron, la cabeza se la hicieron... pero yo lo conoci por esto y esto y lo otro". (...) El Cabo era un criminal, mató a mucha gente. (...) Echaba gente a la sierra; decía: "aqui no te quiero ver en el pueblo. Vete a la sierra con los bandoleros". Una bestia. Las cosas como son " ${ }^{6}$.

En ese mismo sentido se manifiesta la mayoría de los guerrilleros a la hora de explicar la opción que tomaron.

Pero, junto a la represión, actúa otro factor que suele ser previo a ella y que, muchas veces, está en su origen. Nos referimos a la militancia política. El examen de los expedientes de los guerrilleros archivados en el Centro de Estudios Históricos de la Guardia Civil revela que la mayoría de ellos, en torno al $80 \%$, eran conceptuados como personas de ideo-

"Como en el caso anterior, la "Nota Informativa" de la guardia civil hablaba de "bandoleros muertos en encuentro" (Expediente de Serafin Lorenzo de Cara. CEHGC).

Entrevista con Juan Castillo Gómez y Marcela Rubiño. Motril (22 de octubre de 1987).

Entrevista con la viuda de Emilio García Sabio. Motril (11 de abril de 1988).

${ }^{5}$ Entrevista con Fernando Planas (julio de 1985).

${ }^{6}$ Entrevista con el guardia civil Eduardo Ramírez (Málaga, 5 de mayo de 1986). 
logia izquierdista y, en bastantes casos, adscritos a una organización política o sindical de ese carácter. En muchas ocasiones, antes de integrarse en la guerrilla, fueron perseguidos por esa militancia, sobre todo al terminar la Guerra o en los primeros años de la postguerra. Testimonio de ello podemos hallar tanto en sus expedientes como en las causas archivadas en la antigua Capitanía General de Granada cuando se detalla su pasado. También en sus manifestaciones:

"Yo fui antes enlace de ellos (...) Como la Guardia Civil sabía mis andanzas, yo estaba asustado por si me cogían, por si me metian un palo. Un vecino que también era enlace me dijo: "mira Victoriano, que han caído fulano y fulano, así que ándate con vista, que el asunto está malo". Por eso, yo me quedaba muchas noches en el campo. Pero un sargento empezó a venir a mi casa todos los dias (...) yo dije que no sabía nada, porque yo me dedicaba a trabajar (...) me dijo que, como en 15 días no le informase, me mataba, así que me fui a la sierra"?

"Me fui a la guerrilla porque me hacían la vida imposible. Ya en la Guerra fui un revolucionario $y$, siendo casi un niño, estuve en la 55 Brigada, con el comandante Salvador Trujillo Rueda. Fusilaron a mi hermano Antonio porque decian que era enlace; lo mataron poco antes de irme, en Escúzar, con Manuel Romero Muñoz, "Bigotillo", con un hermano de Felipillo y quizás con otro más. Los llevaron al cuartel de Las Palmas; luego los sacaron y los mataron en Escúzar" ${ }^{8}$.

"Mi hermano, que era comunista, era el que tenía más contacto con ellos y quien más los suministraba. Mi hermano y unos de Morale$\mathrm{da}$, los Pititis. Fueron a los Pititis, que eran carpinteros, y los detuvieron. Entonces, un familiar de ellos, que no había sido detenido, le mandó a mi hermano el recado de que iban en busca de él, por lo que se fue a la sierra"s.

Junto a la represión por causas politicas, hubo casos en que el hambre y las expectativas (parece que fomentadas, según veremos) de superarlo en la guerrilla, fueron los móviles que llevaron a la sierra a algunas personas. El fomento de esas ilusiones pudo deberse a la necesidad de nuevos adherentes: de 1986.

${ }^{7}$ Entrevista con el ex-guerrillero Victoriano Sánchez Ramos. Fuengirola (Málaga), junio

${ }^{8}$ Entrevista con el ex-guerrillero Fernando Romero Calvo. Agrón (Granada), 9 de agosto de 1988.

${ }^{9}$ Entrevista con el antiguo enlace de la guerrilla, Rafael Castilla. Granada, 2 de enero de 1988. 
Antonio Campaña Comín [es Cominol, dice: Que se encontraba en Loja trabajando en el campo, donde se le acercó el "Retorcio", paisano suyo, y le propuso marcharse con él a la sierra, donde no se trabajaba nada, se comía bien y se ganaba más, al mismo tiempo que le hacian estas proposiciones, le mostraba unos fajos de billetes que en la sierra había ganado, cantidad, que según le decía, jamás podría llegar a tener trabajando en el campo. Esta propaganda sostenida varios dias, logró convencerle y a otro trabajador que también estaba con él, marchando los tres al Monte" ${ }^{10}$.

Estas manifestaciones las hacia un guerrillero detenido a la Guardia Civil; es posible que para disminuir su futura condena se quisiera mostrar como engañado y empujado a la sierra, pero hemos encontrado otro testímonio de similares características, el de Miguel Martín García, tras ser detenido y, posteriormente, el de su abogado defensor.

«[declara que] se ambientó en las ideas de izquierdas por hallarse sin trabajo en el pueblo y pasando calamidades por cuyo motivo decidió marcharse a las sierras y unirse a las partidas de bandoleros del Roberto, ya que con los atracos que éstos daban podia remediar su situación y ayudar a su familia. A tal fin lo verificó en el mes de febrero de $1947 "{ }^{11}$.

Vive la persona a que nos referimos $y$, aunque intentamos entrevistarlo, se negó, alegando no querer recordar tan malos momentos como los que vivió en la sierra y en la cárcel. Cabe la posibilidad que en las declaraciones transcritas, como en las anteriores de Campaña Comino, exista un componente de tergiversación, pues era su vida la que estaba en juego (el fiscal pidió para él la pena de muerte, y finalmente se le condenó a treinta años de reclusión mayor ${ }^{12}$ pero puede haber cierta verosimilitud si las comparamos con las siguientes manifestaciones:

«En términos generales, los que en aquella época vivían en los cortijos, aunque tuvieran una pequeña manada de cabras, padecían hambre porque los mismos cortijeros no tenían ni hinojos, los tenian que coger para comer. O sea, que el hambre estaba generalizada (...) y

10 Expediente de Antonio Campaña Comino. CEHGC.

11 Causa 1.106/51 contra Álvarez Mesa y Martín García. Folio 12. ACGG.

12 Causa 1.106/51 contra Álvarez Mesa y Martín Garcia. Folio 44, 52 y 81. ACGG. 
habia quien creia que estar en la guerrilla era comer a dos carrillos. Eso lo daba, era fruto del hambre en aquella época, que quedó en la historia como los años del hambre. Y como cuando se llegaba a un cortijo se veía que se comía pollo, bocadillos de jamón y que comian todos los patriotas, pues creian que era comer a dos carrillos. Pero, luego, había veces que estaba uno hasta tres dias sin comer, cuando habia caido la zona" ${ }^{13}$.

Los dirigentes que llegaron a aquella zona procedentes del exilio poseian, como causa común de su incorporación a la guerrilla, su militancia política, concretamente en el Partido Comunista de España. Permanecían en el extranjero desde el final de la Guerra Civil y no sufrieron directamente los rigores represivos de la España ocupada por las tropas de Franco, pues vivieron la contienda en los frentes de batalla, ni tampoco conocieron la postguerra en sus primeros momentos, aunque en algunos casos hubieran pasado por las cárceles del régimen de Vichy, como ocurrió con Ramón Vía y Ricardo Beneyto Sapena. Además de los citados, entre esos dirigentes se encontraban José Muñoz Lozano, "Roberto"; Manuel Lozano Laguna; José Mérediz Víctores; Joaquín Centurión Centurión; Alfredo Cabello Gómez-Acebo y José Sánchez Girón, «PaquiIlo".

Fueron ellos los que se dedicaron a ampliar la formación política antifranquista, y también cultural, de los guerrilleros procedentes del interior que, salvo excepciones, constituian la "base" de las partidas. Sin embargo, la preparación política de los dirigentes llegados del exilio, tenía sus deficiencias. El tipo de la vída que llevaron les hizo más hombres de acción que conocedores, en profundidad, de la teoría política. Santiago Carrillo lo reconocia en una autocrítica realizada el 5 de junio de 1952:

"los camaradas enviados desde Francia... En dos meses [de cursillo] era de todo punto imposible dar a los camaradas todo lo que les faltaba y arrancarles todo lo que les sobraba de deformaciones. El carácter breve de estos cursos estaba determinado por nuestra prisa, por nuestra impaciencia por reforzar el trabajo en el pais (...) los cuadros y militantes enviados desde aquí al pais, al lado de su combatividad y entusiasmo, revelaron... una débil formación política e ideológica y falta de sensibilidad para captar los problemas de la clase obrera y las masas» ${ }^{14}$.

${ }^{13}$ Entrevista con Enrique Urbano. Río de la Miel (Nerja, Málaga), noviembre de 1986.

${ }^{14}$ Morán, G., Miseria y grandeza del Partido Comunista de España 1939-1985. Barcelona, Ed. Planeta, 1985, págs. 191-192. 
Si precaria era la formación política de los dirigentes, más aún la de los guerrilleros surgidos del interior que iban a ser guiados por aquéllos. Aunque se pueden encontrar excepciones, como las de Manuel Jurado Martín, "Clemente", o Manuel Martín Rico, "Ramón", que alcanzaron puestos de responsabilidad, la mayoría no se encontraba en esas circunstancias. Los que poseían un menor bagaje ideológico eran, por lo general, aquéllos que se fueron a la sierra porque un familiar ya lo estaba: colaboraban con él, más que con la guerrilla, y la presión de la fuerza pública les empujó al maquis.

Es fácil constatar en ellos una preparación más deficiente en todos los aspectos, como ocurre con el analfabetismo: en los atestados que se les hace tras ser detenidos, en sus declaraciones o careos, muchos no saben firmar, y lo hacen con la huella dactilar y bastantes son los que, con dificultades, pueden escribir su nombre.

La labor de los dirigentes intentó abarcar tareas culturales y políticas propiamente dichas. Un guerrillero que consiguió escapar a Francia, hacía las siguientes declaraciones al PCE:

«Roberto explicaba cuál era la misión del guerrillero y sobre todo la misión del guerrillero comunista que debía dar el ejemplo. Les planteó como una tarea el aprender a leer y escribir. A esto se dedicaban cuando estaban en el campamento, además de estudiar el Manual del Guerrillero. Se organizaban charlas para enseñarles a hablar" ${ }^{15}$.

La alfabetización era una ocupación prioritaria. Hubo personas que nos han manifestado haber aprendido a leer y escribir en la sierra, como José López Centurión, que antes no pudo ir a la escuela. El recuerdo más vivo que hemos encontrado ha sido el siguiente:

«El que estuviera más capacitado le daba lecciones al que no supiera leer o escribir. $Y$ así aprendió Gutiérrez, en la guerrilla, y el día en que murió, diez minutos antes estaba yo dándole lecciones (...) Nicolás también era analfabeto. $Y$ Roberto le dijo: «si tú supieras leer podrías ser sargento o teniente. Pero tienes que aprender". Y se lo tomó en serio. Entonces se le compró una cartilla. Me acuerdo una vez que veniamos de Almunécar hacia Río de la Miel, de noche, andando, y había tormenta. No llovía pero había tormenta... teníamos que poner un

15 «Información sobre la Agrupación de Granada», pág. 11. ACCPCE. 
pañuelo blanco en el macuto (...) no se veía y estábamos deslumbrados con esos relámpagos. Nos contamos y faltaba Nicolás. Retrocedimos y lo vimos en lo alto de una piedra con la cartilla en la mano, aguardando que hubiera relámpagos para leer. Decia: "la uve con la i, vi.. la ene con la 0, no... vi-no" " ${ }^{16}$.

Un historiador de la guerrilla, Andrés Sorel, recoge un texto de Ramón Vía, en el que se afirma lo siguiente:

«En el orden militar también se han realizado algunos progresos, para lo cual se ha organizado toda una serie de conferencias y operaciones que han servido de mucho (...). En el orden cultural se van realizando algunos progresos. Se dan clases de cultural general, pues la mayoría de los campesinos no saben leer ni escribir" ${ }^{17}$.

Los ex-guerrilleros entrevistados recuerdan también esas facetas políticas y educativas de Ramón Vía, así como de Manuel Martín Rico. De este último, dice Antonio García Ordóñez que les hablaba bastante de su gestión mientras fue alcalde de Nerja durante la Guerra Civil ${ }^{18}$; José García Elena manifiesta que su misión era dar charlas a ellos y a los campesinos, gozando de gran prestigio entre sus compañeros ${ }^{19}$, y Victoriano Sánchez Ramos dice que, durante tres o cuatro meses, le estuvo dando clases a él. Algunos aspectos de esa labor aparecen recogidos en su causa judicial:

“Se dedicó a dar clase a los bandoleros de cultura general e inculcarles las ideas políticas del Partido (...) como secretario general del PC en la sierra, solamente tomaba parte en actos de enseñanzas marxistas" 20 .

Sobre esas enseñanzas añade Enrique Urbano:

${ }^{16}$ Entrevistas con Enrique Urbano. Río de la Miel (Nerja, Málaga) 23-5.84 y noviembre de 1986.

${ }_{17}$ Sorell, A., op. cit., pág. 168.

${ }^{18}$ Entrevista con el ex-guerrillero Antonio García Ordóñez. Salar (Granada), 30-7-90.

19 Entrevista con José Garcia Elena. Almayate Bajo (Málaga), 6-11-87.

${ }^{20}$ Causa 111/51 contra Manuel Martín Rico y José Martín Navas. Folio 6. ACGG. 
«Se hablaba de marxismo en las reuniones de Partido. En las colectivas no: se hablaba contra Franco. También en el periódico se hablaba contra el franquismo, sin hacer política partidista. Con Lozano y Paco, se hablaba de marxismo. De Lenin tenian cosas. Recuerdo que decian que no son las ideas las que determinan la situación económica y social de los pueblos, sino que es la situación económica y social de los pueblos, la que determina las ideas (...) lo mismo charlaba un comunista con otro comunista, discutiendo puntos de vista Clemente con Roberto o con Lozano. Eso no impedia que el que estaba al lado se estuviera enterando y aprendía también (...). Muchos adquieren conciencia en la sierra, porque se les estaba preparando, pero eran la mayoría analfabetos, que veían que se daba escuela y que veía la conducta que teníamos nosotros" ${ }^{21}$.

Pero el carácter del movimiento guerrillero tenía que mostrarse en su práctica explicando, al mismo tiempo, a la población civil que sus actuaciones y los fines pretendidos eran de tipo político; no bastaba, pues, con que asi lo entendieran los componentes de la Agrupación; habia que comunicarlo a los paisanos:

"Todas las acciones que nuestras unidades realicen deben ser de un carácter político y un profundo sentido antifranquista. Nuestro Ejército, eminentemente político, no puede hacer nada más que operaciones políticas. Político es atacar por todas partes a los perros falangistas y sus colaboradores sin la menor consideración, despojándoles de todo aquello que han robado a nuestro pueblo, repartir sus cosechas y ganados entre los necesitados, obligarles a pagar jornales justos a nuestros campesinos y obreros, hacerles prestar sus bestias a aquellos que no las tengan, sabotearles sus negocios, hacerles la vida imposible en sus casas y en sus pueblos. Político e imprescindible es repartir a los hambrientos las existencias de los almacenes de Auxilio Social, (...) ayudar a liberar a los presos, impedir los robos constantes de las comisiones de requisa y las Fiscalías, impedir que las cosechas vayan a los almacenes de los grandes estraperlistas, organizar por todas partes Comités de Resistencia antifranquistas (...) pero todo este trabajo debe completarse organizando mítines y asambleas en cortijos, fábricas, talleres y pueblos, donde se explique sendillamente el objeto de nuestra lucha (...) repartiendo constantemente nuestra propaganda entre la población más cercana a nuestra zona de acción (...) tomando pueblos aunque sea por unas horas y hacer ondear la bandera republicana por todas partes. Tarea principalísima en este orden es que ni una sola operación realizada, por pequeña que esta sea, quede sin explicar polí-

${ }^{21}$ Entrevista con Enrique Urbano. Rio de la Miel (Nerja, Málaga), noviembre de 1986. 
ticamente (...) esto reforzará enormemente las simpatias de los antifranquistas hacia nosotros y aumentará su moral de lucha contra Franco»" ${ }^{22}$.

En general, los guerrilleros sentian una gran admiración por los dirigentes venidos de fuera. En opinión de José García Elena, algunos llegaron a reproducir actitudes de sumisión que, como ocurría en sus pueblos de origen, favorecian comportamientos caciquiles ${ }^{23}$. Esto ocurrio, sobre todo, con Roberto, que lo fomentaba, contándoles su trayectoria en el Ejército republicano y en la Resistencia francesa, así como su vida anterior a la Guerra Civil; les transmitía una imagen de picaro y de brillante militar ${ }^{24}$.

La labor cultural era completada con la lectura de libros como los Episodios Nacionales de Pérez Galdós, que los guerrilleros cargaban en sus mochilas ${ }^{25}$.

«Entonces, uno leía un capítulo y, cuando lo terminaba, se cerraba y hacíamos una reunión entre todos, y hacíamos comentario sobre lo que habiamos leido; se leía en voz alta" ${ }^{26}$.

«Aquello era una escuela (...) se daban clases de política, de combates, había libros, como los de Pérez Galdós" ${ }^{27}$.

\section{GUERRILLA Y BANDOLERISMO: LA CONFRONTACIÓN DE DOS IMÁGENES Y DOS LENGUAJES}

Entre otros factores, hemos mostrado hasta ahora el carácter político de aquellas personas, su conciencia antifranquista y de izquierdas que,

${ }^{22}$ Manual de orientación politico-militar. Ejército Guerrillero de Andalucía. Estado Mayor. Causa 661/52 contra Ricardo Beneyto Sapena, Rafael Armada Ruz, Sebastián Ramos Díaz, Manuel Jiménez Espadafor, José Guirado Parra y Enrique Arroyo Lozano. Folios 2526. ACGG.

${ }^{23}$ Entrevista con José García Elena. Almayate Bajo (Málaga), 6-11, 87.

${ }_{24}$ Entrevista con Enrique Urbano. Río de la Miel (Nerja, Málaga) 10-11-86.

${ }^{25}$ Entrevista con Enrique Urbano, Río de la Miel (Nerja, Málaga), 8-1-84.

Entrevista con el ex-guerrillero José López Centurión. Neria (Málaga), 22-4-88.

${ }^{26}$ Entrevista con Enrique Urbano, Río de la Miel (Nerja, Málaga). Noviembre de 1986

${ }^{27}$ Entrevista con el ex-guerrillero Victoriano Sánchez Ramos, Fuengirola (Málaga), 7-986. 
pese a las deficiencias y excepciones señaladas, no dejó de existir. Por su militancia política les persiguieron e integraron la guerrilla, y objetivos políticos tenía al combatir el franquismo y pretender sustituirlo por una República democrática.

Sin embargo, la denominación que recibian por parte de las fuerzas encargadas de perseguirlos era la de bandoleros. Algunos guardias civiles e historiadores al mismo tiempo, han utilizado también el término, como ocurre con Francisco Aguado Sánchez y Fernando Rivas Gómez. Lo explican, afirmando que el guerrillero defiende a su patria de un enemigo exterior ${ }^{28}$, consideración que nos parece restrictiva pues, aunque la primera vez en que se empleó el término (Guerra de la Independencia española contra Napoleón), respondía a ese tiempo de lucha, tal definición impediria calificar de guerrilas a formas de combate como las llevadas a cabo por los carlistas en el siglo XIX o los castristas y los sandinistas en este siglo, por citar algunos ejemplos.

También coinciden Aguado y Rivas en que los actos realizados ("asesinatos, atracos y secuestros", en palabras de Fernando Rivas), era de tipo bandoleril ${ }^{29}$ por lo que sería adecuado aplicarles ese término.

No obstante, Fernando Rivas reconoce su parcialidad y también la de Aguado, cuando afirma que, al emplear la palabra bandolerismo,

“evidenciamos un talante de censura (...) Francisco Aguado Sánchez desprecia valientemente tal preocupación y muestra una postura decidida, beligerante, de bravío anticomunismo. No podía ser de otra forma (...). Si cuando se hacia historia combatió la guerrilla o el bandolerismo con la espada, no iba a defenderla con la pluma al escribirla" ${ }^{30}$.

El guardia civil Manuel Prieto López, al ser entrevistado por nosotros, explicaba sus preferencias por el término bandolerismo, negando el carácter político de aquellas personas, aunque en cierta medida se 10 reconoce. Para él sólo fueron guerrilleros los dirigentes:

\footnotetext{
${ }^{28}$ Aguado Sanchez. F., El maquis en España. Madrid. Ed. San Martín, pág. 55.

za Aguado Sanchez, F., El maquis en sus documentos (Prólogo de Fernando Rivas). Madrid. Ed. San Martín, 1976, págs. 12-13.

30 Aguado Sanchez, F., El maquis en sus documentos (Prólogo de Fernando Rivas). Madrid. Ed. San Martin, 1976, págs. 12-13.
} 
«El tanto por ciento de políticos era mínimo. No me estoy refiriendo a Ramón Vía y a los diez o doce que vinieron con él desde Argelia. En los años 1948, 1949 y 1950, de doscientos bandoleros habría 10 políticos y creo que me quedo largo".

"Por eso, yo me indigno cuando dicen que eran politicos. Lo que pasa es que al tío que llevan al cuartel y le meten una paliza, si no tiene nada que ver, a la tercera vez se va a la sierra. ¿Políticos?... eso fue todo. Y la inmensa mayoría de esta gente era de izquierdas, to natural por su situación económica, pero apolíticas».

«El guerrillero, el maquis, yo los diferencio del bandolero: unos tíos que vienen de Francia o de Argelia, preparados en una escuela política y se les puede llamar guerrilleros o maquis" ${ }^{31}$.

Resulta significativo que otros guardias civiles nos manifestaran que el término les venía impuesto por sus superiores; se deduce, en palabras de Secundino Serrano, que estaríamos ante una cuestión de estrategia militar ${ }^{32}$ :

"Teniamos orden de llamarlos de esa manera" ${ }^{33}$.

«No se podía decir que eran guerrilleros, porque la situación de España, con Franco... no se podía decir que, no estábamos en paz, y reconocer que había guerrilleros será reconocer que no estábamos en paz, que había una guerra» ${ }^{34}$.

"Una de las genialidades de Don Camilo [Alonso Vega, director general de la Guardia Civil entre 1943 y 1955], fue ordenar que no se les llamara guerrilleros ni maquis, sino bandoleros. Aprovechó que era una palabra con raigambre, sobre todo en Andalucía" ${ }^{35}$

La reciente historiografía ha intentado explicar las causas del empleo del término en cuestión. Según Antonio M. Calero, se pretendia negar «la realidad negándole su nombre. $Y$ así la violencia política es transmutada en delito común" ${ }^{36}$. Para Carlos J. Kaiser, 85.

${ }^{31}$ Entrevistas con Manuel Prieto López. Rincón de la Victoria (Málaga), 9-8-84 y 1-8-

${ }^{32}$ Serrano, S., La guerrilla antifranquista en León (1936-1951). Salamanca. Ed. Junta de Castilla y León. 1986, pág. 29.

${ }^{33}$ Entrevista con el guardia civil, Miguel Galindo. Granada, 4-10-87.

${ }^{34}$ Entrevista con el guardia civil, José Cuenca. Granada, 29-11-86.

${ }^{35}$ Entrevista con el guardia civil, Eduardo Ramirez. Málaga, 5-5-86.

${ }^{36}$ Romeu Alfaro F., op. cit. (Prólogo de A. M. Calero), págs. 9-10. 
«El mero hecho de la persistencia de grupos armados en franca hostilidad al sistema establecido, ponía en entredicho uno de los valores más apreciados e incansablemente ensalzado como logro propio: la paz" "37.

Los historiadores pertenecientes a la Guardia Civil, afirman que emplear el término de bandolero o el de guerrillero sería manifestar simpatia en uno u otro sentido, aunque nos parece más correcta la opinión de Kaiser cuando señala que el uso de la palabra guerrillero no supone cun juicio de valor, sino el reconocimiento de un hecho" ${ }^{38}$.

Pensamos que la diferencia fundamental entre bandolerismo y guerrilla está en sus orígenes y en sus objetivos. Mientras que el primero tiene como fin prioritario la supervivencia y está desprovisto de contenidos, la guerrilla pretende una transformación politica. Las raices del bandolerismo suelen ser socioeconómicas, mientras que las de la guerrilla son políticas, como expresabamos anteriormente. Sólo en algunos aspectos guardan similitudes: su actuación al margen de la ley, el recurso a formas de violencia tales como el homicilio, el secuestro o el robo y la eventual transformación de la guerrilla en bandolerismo cuando abandona sus metas, aunque en algunos casos también el bandolerismo puede devenir en guerrilla.

Pero no fue sólo la palabra bandolerismo. En los documentos de los archivos entonces vinculados al régimen se puede observar la existencia de otros términos, de un lenguaje igualmente peyorativo. Se les llama también forajidos y bandidos; las referencias a la zona republicana durante la guerra civil, cuando se mencionan los antecedentes de los guerrilleros, son del siguiente carácter: “el corrupto frente popular» ${ }^{39}$; la localidad en que vivía "cayó en poder de las Hordas" ${ }^{40}$; «intervino en los demanes de la horda" ${ }^{41}$ y las condenas sufridas por su vinculación a la república, eran por "auxilio a la rebelión" ${ }^{42}$.

Ese lenguaje toma un sentido distinto cuando se refiere al franquismo. De esta forma, en la mayoria de los expedientes citados se habla de GMN ("Glorioso Movimiento Nacional») en la referencias a la guerra civil; las personas de derechas son consideradas "gente de orden" ${ }^{43}$ y los

\footnotetext{
${ }^{37}$ KAISER, C. J., La guerrilla antifranquista. Madrid, Ed. 99, S. A., 1976, págs. 11-12.

${ }^{38}$ KaISER, C. J., op. cit., págs. 12-13.

${ }^{39}$ Expedientes de Francisco Álvarez Megías y Juan Expósito Gálvez. CEHGC.

40 Expediente de Francisco Bonilla Barrionuevo. CEHGC.

${ }^{41}$ Expedientes de Rafael Rodríguez López y Manuel Crespillo Ruiz. CEHGC.

${ }^{42}$ Causa 111/51 contra Manuel Martín Rico y José Martín Navas. Folio 38. ACGG.

${ }^{43}$ Expedientes de Francisco Bonilla Barrionuevo y Antonio Gutierrez Sáez. CEHGC.
} 
pueblos y ciudades de la zona republicana fueron "liberados" por el ejército «Nacional». ${ }^{44}$.

Como en algunos análisis de otras épocas históricas, de todo lo anterior puede deducirse una simbología maniquea, con fines propagandísticos y para facilitar los actos de violencia con el enemigo: sus características son tan reprochables que se puede actuar contra él con la máxima dureza.

La guerrilla generó también un lenguaje propio, no exento de esas connotaciones, incorporando, además, otros aspectos: en vez de emplear el término más neutral de "enlaces", se utilizó el de "patriotas"; a los robos y secuestros se les denominaba "golpes económicos" y es frecuente, en sus documentos, leer palabras como "perro falangista".

Los guerrilleros vestían un uniforme que, junto al mimetismo necesario para camuflarse en la sierra, incorporaba un brazalete con los colores de la bandera republicana, símbolo que resume el pasado que se quería reivindicar y que expresaba la continuidad con el mismo, recogiendo, asi, las orientaciones del Manual de guerrillero:

"Nuestro Ejército y lo que fue Ejército Popular se convirtió en las nuevas condiciones de la lucha, al seguir los mejores de sus componentes al combate en las montañas, en el Ejército guerrillero, con los mismos objetivos que tuvieran el 36-39 en el Ejército Popular" ${ }^{45}$.

Otros aspectos de la vestimenta denotaban los componentes igualitarios de su ideología:

"Nosotros estábamos uniformados casi al estilo militar: pantalón de pana, camisa caqui, cazadora de pana, y todos iguales. En el que fuera jefe o subjefe no había ningún distintivo; teniamos boina azul $y$, todos, la bandera republicana en el brazalete, con las letras ENG (Ejército Nacional Guerrillero) (...). El caqui es el color que más se adapta al monte. Los pantalones de pana los cogiamos de color marrón, no podían ser verdes, sí de color castaño, con lo que se aplastaba uno y, si no se movía, no se notaba la distancia» ${ }^{46}$.

${ }^{44}$ Expedientes de Antonio Garcia Caballero y José Garcia Expósito. CEHGC.

${ }^{45}$ Manual de orientación.. Causa contra Ricardo Beneyto... Folios 23-24. ACGG.

${ }^{46}$ Entrevista con Enrique Urbano. Río de la Miel (Nerja, Málaga) 3-11-86. 
Volviendo a los contenidos maniqueos, en el análisis de la documentación podemos observar cómo fueron fomentados por los dirigentes guerrilleros en su labor educativa.

El Manual de orientación político-militar del Ejército Guerrillero de Andalucía, junto a otros objetivos didácticos ya mencionados, expresaba el deseo de la dirección de hacer llegar una serie de ideas a las mentes de los guerrilleros, que debían ser asimiladas empleando las técnicas pedagógicas de la memorización, el debate y la práctica:

«Ante el gran desarrollo de nuestro Ejército Guerrillero de Andalucía, tan glorioso, y por la mucha movilidad de nuestras unidades, como consecuencia de las características de nuestra lucha, que impide en muchas ocasiones tener con ellas un contacto regular y continuo, decidimos hacer este pequeño Manual que recuerde constantemente a nuestros combatientes el carácter político-militar de nuestro Ejército y el de cuantas acciones realicemos. Cada uno de nuestros hombres debe de poseer un ejemplar, leerlo y releerlo hasta aprendérselo de memoria, asimilándolo en discusiones colectivas y aplicarlo con inteligencia en todas las ocasiones propicias. Ayudará mucho a los nuevos incorporados y servirá a los veteranos de recordatorio sobre las normas a las cuales debemos ajustar todas nuestras acciones. Tratamos de evitar en todo lo posible errores, desviaciones y faltas en que algunas ocasiones, cuando se cometen, desvirtúan el verdadero carácter de nuestro Ejército y también de nuestra personalidad politica antifranquista» ${ }^{4}$.

Las imágenes transmitidas por la dirección pueden estudiarse a partir del análisis de la canción que enseñaron a los maquis y que constituyó el himno guerrillero ${ }^{48}$. La imagen de los guerrilleros es absolutamente positiva: poseen la libertad, son los mejores combatientes, que no ceden ante las dificultades y que conseguirán la victoria. Hay pocas referencias al enemigo: será derrotado, y desean la muerte de Franco, idea, esta última, que sustenta la contrapuesta, el triunfo de la libertad. Las palabras de autoadulación pueden interpretarse como la necesidad de dotarse de ánimos en circunstancias difíciles, de ahi que se entonara al llegar uno de los peores momentos por los que había de atravesar la vida del guerrillero: la entrada en combate.

47 Manual de orientación... Causa contra Ricardo Beneyto. Folio 22. ACGG.

${ }^{48}$ Entrevista con Enrique Urbano. Río de la Miel (Nerja, Málaga), 10-11-86. Aún recuerda la letra del himno que, con leves variantes, es recogido por Aguado en El maquis en sus documentos, pág. 447. 
En total contraposición a la visión que de los guerrilleros propagaba el Régimen, los dirigentes transmitían a aquellas personas, que antes de marchar a la sierra habían sido humilladas, una imagen de heroísmo.

Otra de las canciones guerrilleras era la titulada «Del Cáucaso a la Siberia». Describe al enemigo con caracteres totalmente negativos: Ilevado por el odio, incendia, mata y arruina al pueblo; trae esclavitud, hambre, opresión, persecución a la ciencia, a la cultura, al trabajo; dominando a este pueblo, pretenderá hacerlo con el resto del mundo, pero será vencido y se hará justicia ${ }^{49}$.

Esa mentalidad, uno de cuyos componentes es también el rechazo a la idea de bandolerismo, se traducía, entre otras medidas, en no permitir,

«Patillas largas; cuando salíamos de patrulla teníamos que salir todos afeitados; no se permitian apodos. Eran las normas que teniamos y que nos inculcaba el Estado Mayor. Se trataba de evitar la identificación con los bandoleros que tanto abundaron en Andalucia" ${ }^{50}$.

"Cuando íbamos al Llano se lucía el mejor armamento, que era verdad que estábamos muy faltos de armamento, pero lucíamos las mejores metralletas, las mejores pistolas, las mejores escopetas, para animar a la gente (...) Cuando llegábamos nosotros a una charla íbamos afeitados, preparados, vestidos de limpio" ${ }^{51}$.

Asimismo, procuraron dar un sentido político a sus actos y transmitirlo a sus colaboradores, a los que ayudaban económicamente:

«En los cortijos pagábamos con el dinero que sacábamos, que no era a un cualquiera, sino a un fascista señalado por la gente del pueblo, que se habia incautado de propiedades del pueblo y que nosotros devolvíamos al pueblo. También mandábamos dinero a los encarcelados. No era dinero para andar con mujeres (...) Ya no nos podian acusar de ladrones. Los cortijeros pasaban hambre y, si les quitábamos cosas, era ésa una política en contra nuestra. Lo único que teniamos que hacer es que el pueblo viera que les ayudábamos. en las charlas les deciamos

49 Entrevista con Enrique Urbano. Río de la Miel (Nerja, Málaga), 10-11-86.

Aguado SANChEz, F., op. cit., pág. 443-444.

50 Entrevista con Enrique Urbano. Río de la Miel (Nerja, Málaga), noviembre de 1986.

${ }^{51}$ Entrevista con José García Elena. Almayate Bajo (Málaga), 6-11-87 y 15-11-87. 
que éramos la vanguardia y ellos la retaguardia, y les dábamos la misión de que nos compraran la comida, dándoles dinero" ${ }^{52}$.

El Manual de orientación politico-militar, coincidiendo con las ideas expuestas por el ex-guerrillero citado, señalaba al respecto:

"Nuestro comportamiento ha de ser ejemplar como corresponde a hombres que luchan por un régimen justo y humano; caer en los mismos vicios que los señoritos falangistas es desprestigiar nuestro glorioso ejército guerriliero, a nuestros héroes caídos en la lucha y a la causa por que lucha nuestro pueblo, y a nosotros, la vanguardia. Cada uno de nosotros tiene la obligación de reprimir y vigilar todos aquellos actos que puedan dar pie a nuestros enemigos para su propaganda contra nosotros ${ }^{53}$.

En las zonas rurales de Granada y Málaga subsistia, en la postguerra, la cuestión del bandolerismo, pero el bandolerismo "real», en el sentido más riguroso de la palabra, heredero del que hubo en el siglo xIX y primer tercio del $x x$. La guerrilla se oponía a él y lo combatió por varias razones: las acciones cometidas por ellos se las podian imputar, desprestigiándola, mientras que el hecho de perseguirlos acrecentaría la fama de la guerrilla en los sectores populares que verían en ésta a un defensor de sus intereses. Nuevamente hay concomitancia entre lo deseado por los dirigentes y las manifestaciones de nuestros interlocutores.

«Hay que liquidar la mala hierba del bandolerismo y de la provocación. Allí donde surgía esta inclinación, individual o colectivamente, hay que reprimirla con mano de hierro sin la menor vacilación (...) Los verdaderos bandoleros son protegidos por la Guardia Civil y los falangistas, a los que sirven directamente como espias, confidentes y agentes provocadores, se les permite robar y asesinar impunemente, son hombres sin conciencia ni moral, sin principios políticos y sólo ajustan su actuación al robo vulgar en beneficio propio (...) Ni un solo bandolero debe infiltrarse en nuestras filas ni habitar en nuestra comarca, provincia o región; la limpia de degenerados de esta calaña hará que nuestro pueblo tenga gran confianza en nosotros" ${ }^{54}$.

${ }^{52}$ Entrevista con Enrique Urbano. Río de la Miel (Nerja, Málaga), noviembre de 1986

${ }^{53}$ Manual de orientación... Causa contra Ricardo Beneyto... Folio 27.

${ }^{54}$ Manual de orientación... Causa contra Ricardo Beneyto... Folio 27. 
Algunos guerrilleros se han expresado en los mismos términos: los bandoleros que actuaron en la zona tuvieron que huir ante la presión de la Agrupación Guerrillera, que en algún caso llegó a darles muerte ${ }^{55}$.

\section{VIDA COTIDIANA DEL GUERRILLERO: PENALIDADES, PAPEL DE LOS ENLACES EN EL ABASTECIMIENTO, ALIMENTACIÓN, ECONOMIA GUERRILLERA Y ALOJAMIENTO}

Es difícil encontrar en los documentos escritos de la época vinculados al maquis, el testimonio de las penalidades sufridas por la guerrilla. Si abundan las referencias a la vida de los paisanos y, sobre todo, de los enlaces o de las personas de izquierdas: represión, difíciles condiciones laborales, altos precios y hambre son temas frecuentes en esa documentación. Referirse a los sufrimientos de los guerrilleros, podía desalentar nuevas adhesiones al movimiento armado. Como en otros casos, donde no llega la documentación escrita, sí lo hacen las fuentes orales, que explicitan las dificultades sufridas.

Los ex-guerrilleros son conscientes de haber actuado en un medio hostil, dominado por el adversario y donde no tenian las facilidades de apoyo que hubo en la zona republicana durante la Guerra Civil; la clandestinidad de las ayudas recibidas y el consiguiente peligro a que se exponían sus líneas de abastecimiento, determinaban la escasez o la ausencia de este último:

"Si tienes una zona que te respalde, donde comes y descansas, es distinto. Pero nosotros estábamos en el corazón del enemigo" ${ }^{56}$.

“Unas guerrillas como las que teniamos eran bien distintas a lo que pasó en la Guerra Civil: llegabas a la retaguardia y tenías vino, agua e, incluso, si llegaba el caso, mujeres. Alli no existía nada de esto" ${ }^{\text {s? }}$.

Las dificultades son recordadas por algunos con bastante detalle, como un componente de la vida cotidiana del guerrillero:

55 Entrevista con Antonio Garcia Ordóñez. Salar (Granada), 30-7-90. Sorel., A., op. cit., pág. 168-169.

56 Entrevista con Fernando Romero Calvo. Agrón (Granada), 9-8-88.

${ }^{57}$ Entrevista con José García Elena. Almayate Bajo (Málaga), 6-11-87. 
"Una vez estuvimos varios días sin comer, y lo que comíamos eran puntas de zarza, de penca, de berros, lo que daba el campo (...) y llegar a un cortijo, abrirlo, y había alli harina, de lo que fuera, y echarnos agua y un puñado de harina, moverlo, y a comerlo (...) la harina tenía pelusas de todo. Entonces yo fui más para abajo, pensando encontrar algo. No había más que mazorcas, que cuando están empezando no tienen nada, todo está muy blando, hasta el tronco, pues empezar a quitarle la hoja y comerla (...) Yo he estado en Torrox en una haza de cañas, y comiendo nada más que caña durante varios dias. Y es que la Guardia Civil estaba dando unas batidas terribles (...) Durante una travesia comíamos lo que econtrábamos, pasas, higos podridos, pimientos (...) Menos las habichuelas, que es lo único que yo no he podido tragar, ni tampoco muchos compañeros: comerlas crudas y sin sal (...) Estábamos deshechos; no había fuerza en los cuerpos para poder seguir, pero antes de eso estuvimos tres días en un sitio, había allí un cortijo abandonado; nos metimos alli y las pencas naciendo, para nosotros eso eran rosquillas, y las puntas de las uvas que estaban naciendo, todo eso nos lo comíamos.

En un sitio de la Sierra de Loja, en un agujero, una vez estuvimos dieciséis. Se levantaba una piedra y nos metiamos. En aquella ocasión venía Pita, de Torrox, era el cocinero, ya muy mayor tosía y le decíamos: «Pita, si toses te ahogamos» $Y$ él respondía: “haced lo que querais antes de que murais todos".

Nosotros veíamos los zapatos de los Guardías, mirando por arriba; los oiamos charlar, y nosotros metido alli; no podiamos fumar, ni hablar, ni nada. Alli estuvimos metidos desde la madrugada, todo el día, con la Guardia Civil arriba; alli hicieron guiso, nos enteramos de todo lo que hablaban, y aquello era profundo, era como una vereda que cabía un hombre no muy alto, pero agachados y al lado de Pita, dos con mantas... un tosido y lo ahogaban alli (...) No había cartas ni habia nada para la familia. Únicamente que uno llegara y le contara de la familia: "pues mira, está por la parte de Granada, está por cualquier lado". La familia a veces tiraba más que la ideología, eran seres humanos y querian verla (...) El mayor peligro estaba cuando íbamos a por agua, pues nos estaban esperando. Sabían que no teníamos más remedio que ir por ella para hacer la comida (...) Aquello se fue endureciendo; hubo muchas muertes; cada dia había más emboscadas, más apostaderos, y venían grupos a los que le habían matado a fulano y a mengano (...) habia grupos que de diez, habian quedado siete, otros con ocho, uno vino con cinco, los demás murieron. En Granada los apostaderos en esos sitios eran terribles, porque hay muchas ramblas $y$, cuando te cogian en una rambla, tú no tenias donde meterte" ${ }^{58}$.

«En la sierra pasamos mucha hambre y miseria, soportando la lluvia, la nieve, que a veces teníamos que atravesarla cubiertos hasta la cintura, y sin comer" ${ }^{59}$.

\footnotetext{
${ }^{58}$ Entrevista con José García Elena. Almayate Bajo (Málaga), 6-11-87.

${ }^{59}$ Entrevista con Fernando Romero Calvo. Agrón (Granada), 9-8-88.
} 
La abundancia de pequeños cortijos en esta zona de Andalucia, de hábitat disperso, llevó a la Guardia Civil a recoger por las noches las llaves de los mismos; sus moradores permanecían en ellos encerrados, hasta el día siguiente. En ocasiones, tal medida se practicaba con pueblos enteros, como ocurrió con Agrón y, otras veces, se obligó a sus habitantes a abandonar sus casas de campo, marchando a las ciudades. Con ello los Guardias pretendían cortar el abastecimiento que, de noche, recibian los guerrilleros o que se refugiaban dentro. Estos datos, corroborados por nosotros en el pueblo de Agrón, en julio de 1987, aparecian en Andalucia: Campo de Trabajo y Represión, del periodista granadino Antonio Ramos Espejo. El Guardia Civil Manuel Prieto López, también nos informa al respecto, describiendo otros métodos de la fuerza pública para cortar el abastecimiento y el refugio al maquis y provocar las dificultades antes señaladas:

«Agrón aportó 22 guerrilleros. Cayeron todos, menos cuatro. Durante los años más duros de la "represión maquis" la Guardia Civil convertía todo el pueblo en una cárcel nocturna. Cuando los trabajadores volvían del campo, la Guardia Civil echaba las llaves a todas las puertas y, además, les colocaba un precinto. Si el precinto aparecía roto o forzado por la mañana era señal de que alguien había querido salir. Por las mañanas, la Guardia Civil abria las puertas» ${ }^{60}$.

«Entonces, en los cuarteles (recuerda lo que te decía de la fuerza que uno tenia, que hacía lo que le daba la gana), teniamos las llaves de todos los cortijos, y como eran antiguas, de unos 15 o 20 centímetros, las teníamos en las paredes: en una pared, tenía todo el cuartel las llaves de los cortijos de su demarcación; el que menos, tenia mil llaves. Es curioso, porque entras en un cuartel... ya algunos estarán derrumbados; en aquel entonces estaba todo lleno de cortijos pequeñitos, que aprovechaban al lado para extender la uva. Teníamos esto por dos razones: una para que no pudiesen entrar los bandoleros sin saberlo nosotros, pues tendrian que romper la puerta; otra, porque a veces nos metíamos y esperábamos un día, o dos, o tres (...). Siendo yo teniente de Jayena, tenía tal autoridad que era amo y señor, y lo que yo hacía iba a misa; asi, uno de los procedimientos por el que se suministraban los bandoleros, eran los que salian a resinar, los resineros. Alli está la Unión Resinera, en Jayena y en el pinar de Alhama (...) De esa resina, que recogen en una taza, sale el aguarrás, la colofonia, etc. Creo que se empezaba a resinar por marzo. Pues yo prohibi que se resinase, y aquel año no se resinó" ${ }^{61 .}$.

${ }^{60}$ Ramos Espejo, A., Andalucia: Campo de Trabajo y Represión. Granada. Ed. Algibe, 1978, pág. 468.

${ }_{61}$ Entrevista con Manuel Prieto López. Rincón de la Victoria (Málaga), 9-8-84. 
Vigilancia especial recibian los familiares de los guerrilleros; de ellos esperaba la Guardia Civil que ejercieran de enlaces. Como medida preventiva, si no habian sido descubiertas comunicándose con la guerrilla, bastantes mujeres fueron encarceladas: eran madres, esposas, novias 0 hermanas de los guerrilleros que, en alguna ocasión, dieron a luz en la cárcel. En las entrevistas nos han manifestado que preferían seguir presas a que las pusieran en libertad, pues esto último se hacía cuando el guerrillero había caído. En la zona de Salar y Alahama de Granada fueron obligadas, junto con otros enlaces varones, a recorrer la sierra gritando el nombre de sus familiares guerrilleros; la Guardia Civil procuraba que estos últimos aparecieran y poder eliminarlos; no lo consiguieron con este método, entre otras razones, por el poco empeño que pusieron en la labor asignada ${ }^{62}$. En bastantes ocasiones fueron sometidos a palizas y torturas y muchos de los enlaces que murieron por la aplicación de la ley de fugas, eran familiares de los guerrilleros. El padre de los hermanos Jurado Martín, perdió a sus tres hijos: Rafael en el encuentro de Cerro Verde y Manuel Antonio fueron fusilados; a su yerno (José Cuesta Ortega, "Paemonda", mencionado anteriormente por nosotros) le aplicaron la ley de fugas; tras haber pasado por la cárcel y haber sufrido diversas presiones, emigró a Barcelona donde se quitó la vida arrojándose bajo un tren en marcha ${ }^{63}$.

La alimentación de la guerrilla dependía de lo que ofreciera la zona de actuación; era también distinta si estaban de marcha o estacionados en un campamento, existiendo un régimen aparte para los enfermos. Asimismo, el almacenamiento de la comida era un problema que necesitaba de soluciones. En todo ello la labor del enlace era capital, de él dependía en buena medida, la resistencia de la organización guerrillera, y su labor, aunque diversa, pues suministraba información, vestimenta, medicinas, armas y era el cauce de propaganda, tenía como fin prioritario abastecer al maquis de alimentos:

"Decíamos a un patriota que nos suministrara tantas latas de sardinas... más que nada rancho en frío, porque para nosotros, cuando

${ }^{62}$ Entrevista con Ana López González y Encarnación Martin Cervera. Salar (Granada), 13-8-87.

Entrevista con Rafael Castilla Sánchez. Granada, 2-1-88.

63 Entrevista con Fernando Álvarez Mesa. Torrox (Málaga), 24-3-85. Expedientes de los hermanos Jurado Martín en CEHGC. Causa contra Manuel Jurado Martín, Antonio Jurado Martín y José Martin García. Folio 148. ACGG. 
íbamos de marcha... al estar en posición, sí... entonces se hacian migas. Y el pan lo guardábamos más que nada para las salidas, para las patrullas. A lo mejor teniamos un jamón y cogíamos medio kilo o tres cuartos de kilo, y el pan (...) el jamón era más alimento y, como teníamos que llevar a cuestas, queríamos cosa que alimentara mucho y pesara poco (...) cogíamos latas de atún dos días (...) Los que estaban en Sierra Nevada, alli la carne a voluntad, porque estaba la ganaderia de Pelayo, que era un oficial de la Guardia Civil (...) En la Sierra de Loja había muchas manadas de cerdos en libertad (...) algunos guerrilleros los mataban dándole con una piedra en la cabeza, y el cerdo no chillaba" ${ }^{64}$.

“Migas se comian muchas. Migas de trigo (...) por la parte de la costa las hacian de maíz, en esta zona [Vega de Loja] no; en esta zona abunda más la de trigo que la de maíz. Garbanzos, arroz, arroz con lentejas (...) Cuando saliamos de marcha llevábamos pan y rancho frío. $Y$, luego, ya ibas suministrando por las zonas que fueras, pero a lo mejor te metías en una zona que no conocías mucho y tenías que llevar más comida (...) En la sierra había piaras de cerdos sueltos, también podíamos matar un toro o una vaca, pero eso era de tarde en tarde (...) los garbanzos, las harinas, el arroz, latillas de conserva, latas de chorizo, de morcilla (...) Y aquí habia veces que subian hasta 20 y 30 , cargados todos con medio saco de harina. $Y$ otras veces la sacaban con bestias, según la zona que fuera y lo castigada que estuviese. Si estaba la zona muy tranquila, había gente que echaba valor y cogía dos y tres bestias y se llevaba las cargas de harina alli arriba" ${ }^{65}$.

Según Enrique Urbano, a los enlaces les instruían en la norma de no comprar gran cantidad de suministro en la misma tienda y el mismo día, para evitar sospechas del tendero. $Y$ es que, tal como nos cuenta Manuel Prieto, el control de las tiendas y de las farmacias era una de las labores de la Guardia Civil: los dependientes tenian que dar noticia a la fuerza pública de las personas que compraran gran cantidad de productos. El dinero que la guerrilla daba a sus enlaces para el abastecimiento era en moneda fraccionaria; se evitaban así otras sospechas, pues el que una persona pobre pagara con un billete de mil pesetas provocaba extrañeza en el tendero ${ }^{66}$.

En los primeros años de la guerrilla, eran los enlaces quienes proporcionaban el dinero pero, más tarde, se invirtió la situación, consiguiéndose los fondos a partir de los "golpes económicos" (atracos y secues-

${ }_{64}^{64}$ Entrevista con Enrique Urbano. Río de la Miel (Nerja, Málaga), 8-1-84.

${ }^{65}$ Entrevista con Antonio García Ordóñez. Salar (Granada), 30-7-90.

${ }^{66}$ Entrevista con Manuel Prieto. Rincón de la Victoria (Málaga), 9-8-84. Entrevista con Enrique Urbano. Río de la Miel (Nerja, Málaga), noviembre de 1986. 
tros) y procurando pagar a los enlaces por el trabajo y el riesgo de abasticimiento. En este punto hay una coincidencia, casi textual, entre las normas que, según dos ex-guerrilleros, le transmitian los dirigentes y las consignas que se encuentran en el Manual de orientación político-militar de la Agrupación Guerrillera Granadá-Málaga:

«En la época de Ramón Vía, antes de irme a la sierra, los enlaces haciamos suscripciones para la guerrilla. Teníamos la ración de tabaco que recibiamos cada diez días y la mitad de la ración se la dábamos a la guerrilla. Como éramos tantos los organizados, podíamos casi abastecer a la guerrilla. También, según las posibilidades de cada uno, daba dos o tres pesetas, porque en aquel tiempo los jornales estaban a cuatro pesetas. Cuando llegó Roberto se hizo al revés: él nos decía: "en vez de tener fondos del pueblo, que está hambriento, somos nosotros quienes hemos de ayudarles a ellos". Y lo formó de otra manera. (...) A los patriotas, por hacer el trabajo se le pagaban los jornales y se les ayudaba; eso era la "Soli" (...) Roberto nos decía: "no somos nosotros quienes tenemos que sustentarnos del pueblo. Somos nosotros los que tenemos que ayudar al pueblo. $Y$, ¿cómo le vamos a ayudar?... pues ¿quién tiene las perras?... los fascistas. De las costillas de los fascistas tienen que salir los recursos para la lucha $y$, al mismo tiempo, para ayudar a los patriotas". Que entonces fue cuando se empezaron a realizar las operaciones de tipo económico" "67.

“Ten en cuenta que, a lo primero, no se daban golpes económicos; a lo primero, se recibia dinero, había patriotas que lo daban. El secuestro vino después" ${ }^{68}$.

Por su parte, el Manual de orientación político-militar, señalaba:

"Las necesidades de nuestros alistados deben ser cubiertas por nuestros enemigos falangistas y sus colaboradores, y es solamente de las espaldas de éstos de donde deben salir nuestros recursos. Golpear a ciegas o sobre simpatizantes de nuestra causa es un grave error que hay que evitar a toda costa" ${ }^{69}$.

Por lo general se aplicó esa norma, actuándose mediante el atraco o el secuestro contra personas vinculadas al franquismo y que poseian

${ }^{67}$ Entrevista con Enrique Urbano. Rio de la Miel (Nerja, Málaga), 3-11-86.

${ }^{68}$ Entrevista con José García Elena. Almayate Bajo (Málaga), 6-11-87.

${ }^{69}$ Manual de orientación... Causa contra Ricardo Beneyto... Folio 26. ACGG. 
una riqueza considerable. Si había sospechas de que una persona era confidente de la fuerza pública se le ponía, como represalia, una "multa» que tenía que pagar; en otros casos se le daba muerte. Sin embargo, hubo ocasiones en que el represaliado no tenía la capacidad económica sospechada por la guerrilla y sufría la violencia de ésta. Ese fue el caso de Manuel Villalba Fernández, secuestrado el 22 de septiembre de 1951 en el municipio malagueño de El Borge; a su familia se le exigió 100.000 pesetas y, al no entregarlas mataron al secuestrado. En la causa abierta con motivo del asesinato se afirma que la familia hizo gestiones para conseguir el dinero y que el muchacho llegó a decir que su padre no podía conseguir ese dinero ni aún vendiendo sus escasas propiedades ${ }^{70}$.

Otro secuestrado, José Bueno, nos manifestó que alcanzó la libertad previo pago por su padre de 100.000 pesetas. La razón del secuestro fue, tal como le manifestaron los guerrilleros, que su padre habia entregado a la Guardia Civil a un enlace que fue eliminado, pero José Bueno asegura que la guerrilla estaba confundida y que su padre no tuvo relación con la captura y muerte de esa persona ${ }^{71}$.

Los fondos de la guerrilla estaban recogidos, por escrito, en una libreta de contabilidad, con especificación de ingresos y gastos; el control era riguroso, teniendo que justificarse los gastos cada mes. Los papeles de contabilidad eran escondidos en cajas de latón, que, luego, se enterraban en la sierra ${ }^{72}$.

La "Soli", mencionada anteriormente, era el nombre que recibia la paga de la guerrilleros; consistía en 500 pesetas al mes aunque nuestros interlocutores señalan que, cuando los fondos escaseaban, no recibian la paga, lo que ocurrió con bastante frecuencia. Ese dinero lo destinaban unas veces a su familia, otras a campesinos que pasaran necesidades $y$, especialmente, a los enlaces ${ }^{73}$.

Para dormir hacian tiendas de campaña con toldos, mantas, o con lienzos de los empleados en los paseros y un palo que lo sujetaba;

${ }^{70}$ Causa 950/51 por el secuestro y asesinato del vecino de El Borge (Málaga), Manuel Villalba Fernández. Folio 2. ACGG.

71 Entrevista con José Bueno. Torrox (Málaga), 29-12-84.

${ }^{72}$ Entrevista con Fernando Romero Calvo. Agrón (Granada), 9-8-88.

Entrevista con Enrique Urbano. Río de la Miel (Nerja, Málaga), 81-84. Entrevista con Antonio Garcia Ordóñez. Salar (Granada), 8-8-87.

${ }^{73}$ Entrevista con Fernando Romero Calvo. Agrón (Granada), 9-8-88.

Entrevista con Enrique Urbano. Río de la Miel (Nerja-Málaga), 8-1-84.

Entrevista con Antonio García Ordóñez. Salar (Granada), 30-7-90.

Entrevista con José García Elena. Almayate Bajo (Málaga), 6-11-87. 
procuraban buscar lugares de fácil camuflaje y evitaban descansar en el interior de los cortijos o en cuevas, por su difícil salida. Ponian a algún vigilante de imaginaria $y$, a veces, a otro que hacía las veces de escucha junto al camino ${ }^{74}$.

\section{MENTALIDAD Y RELACIONES SEXUALES}

Las relaciones sexuales estaban prohibidas, lo que originó algunos conflictos. Tenemos noticias de un homosexual que fue censurado cuando se supo que quiso relacionarse con otro guerrillero. Con respecto a las mujeres, no hubo ninguna en esta Agrupación Guerrillera, aunque muchas actuaron como enlaces. Hubo quien intentó transgredir las prohibiciones, siendo también sancionado; fue el caso de Francisco López Pérez, "Paco» y «Polopero" que, por querer insinuarse con la hija de un enlace, fue degradado de capitán de compañia a teniente ayudante:

"¿qué opinión iba a tener el patriota ese, cuando la hija le diga que un guerrillero la ha tocado, mientras él estaba jugándose el pellejo y la cárcel por ir a abastecernos a nosotros? ${ }^{75}$.

Francisco López Pérez antes de incorporarse a la Agrupación Guerrillera Granada-Málaga, habia estado en otra organización que actuaba en Sierra Nevada y las Alpujarras y parece que las normas allí eran de otro tipo, por lo que le costó adaptarse a la nueva situación:

«Surgían rencillas por las cosas más pequeñas (...) teníamos prohibidas las mujeres, pero Paco habia estado antes en la Agrupación de Granada y alli no se prestaba atención a esto.

Al faltar contacto con el Estado Mayor, Paco tendió a buscar las mujeres. Esto daba lugar a discusiones" ${ }^{76}$.

74 Entrevista con José Elena. Almayate Bajo (Málaga), 15-11-87. Entrevista con Enrique Urbana. Río de la Miel (Nerja, Málaga), 8-1-84 y 10-11-86.

${ }^{75}$ Entrevista con Enrique Urbano. Rio de la Miel (Nerja, Málaga), noviembre de 1986.

${ }^{76}$ "Información sobre la Agrupación de Granada". Movimiento guerrillero. Caja 2, Carp. $4 / 2$, págs. 8-9. ACCPCE. 
Hubo también casos en el sentido contrario, es decir, guerrilleros que recibieron proposiciones femeninas y que, en alguna ocasión rechazaron tempestuosamente ${ }^{77}$. Un motivo de esa contención sexual era el deseo de evitar distracciones en su labor, pues hubo ocasiones en que la Guardia Civil pudo sorprender a guerrilleros que estaban tratando a unas chicas, y un enfrentamiento con los Guardias que originó dos muertes en las filas del maquis por haber visitado a un cortijo donde esperaban encontrar a unas mujeres y que estaba vigilado por la fuerza pública ${ }^{78}$.

Quizás una mentalidad puritana que, en algunos casos, veía a las mujeres como elemento de corrupción, explique también la prohibición de tratarlas o que se incorporaran a la guerrilla.

Esa mentalidad se deduce del recuerdo de algunos guerrilleros y enlaces que achacan a una mujer la caída del jefe del maquis granadinomalagueño. Nos referimos a la detención en Madrid, cuando preparaban la huida, de Roberto y de Ana Guriérrez Rodríguez, "Tangerina", sentimentalmente unidos desde unos meses antes: hay quienes dicen que fue ella la que to entregó; otros manifiestan que fueron capturados porque Roberto había descuidado sus obligaciones, atendiendo más a Ana Gutiérrez. Pero no hay referencia documental alguna en ese respecto, y del análisis de la causa celebrada contra ambos que desprende que la caida pudo tener otras causas.

Como otros aspectos que hemos visto del imaginario colectivo (entre ellos el maniqueísmo), esa mentalidad puritana y a veces agresiva con la mujer, parece ser compartida por Guardias, como Francisco Aguado, que afirma lo que sigue:

“Roberto (...) con una gran experiencia como atracador y terrorista (...) y no menos énfasis y entusiasmo, en el que, dicho sea de paso, le anima su novia apodada "La Tangerina" ${ }^{79}$.

Esas imputaciones contra Ana Gutiérrez no aparecen en ningún momento a lo largo de la causa seguida contra ella; ni en los atestados, ni en los antecedentes que investigó la fuerza pública; tampoco en las in-

${ }^{n}$ Entrevista con Enrique Urbano. Río de la Miel (Nerja, Málaga), noviembre de 1986.

${ }^{78}$ Entrevista Urbano. Rio de la Miel (Nerja, Málaga), noviembre de 1986.

79 Aguado Sánchez, F., Historia de la Guardia Civil (6). Madrid, Cupsa Editorial, 1985, págs. $330-331$ 
La agrupación guerrillera Granada-Málaga: estudio sobre las ...

dagaciones del juez instructor, ni en las acusaciones del fiscal o en la sentencia. Había conocido a Roberto a finales de mayo de 1951, cuando abandonó la sierra, sin volver a actuar en la misma, y fueron detenidos en septiembre del mismo año ${ }^{80}$.

\section{CONCLUSIONES}

Las imágenes que transmitieron, tanto el movimiento guerrillero de postguerra (en nuestro caso la Agrupación Guerrillera Granada-Málaga) como sus oponentes, se expresaron mediante un lenguaje distinto que encontró su culminación a la hora de calificar aquel movimiento con los términos opuestos de bandolerismo y guerrilla. A nuestro entender, el rigor histórico debe llevar a la asunción del segundo de estos términos, sin que ello suponga aceptar el maniqueismo que a él se ha vinculado.

El análisis y la contrastación de las fuentes que hemos manejado nos ha permitido, también, descubrir la intencionalidad existente en el conjunto de símbolos (entre ellos el lenguaje) que se emplearon, apreciando el papel determinante, en muchos aspectos, de las cúpulas dirigentes tanto del movimiento guerrillero, cuyas ideas se plasmaban en el Manual y que en bastantes ocasiones trascendian a la práctica, como de la Guardia Civil.

Hemos estudiado, asimismo, diferentes aspectos de la vida cotidiana del guerrillero, en la que la mentalidad se conjugaba con la necesidad y la adaptación a las circunstancias. En este campo jugaban un papel trascendental los enlaces, principalmente soportes de la organización y objetos, por tanto, de los rigores represivos.

${ }^{80}$ Causa 939/51 contra José Muñoz Lozano(a) Roberto, Francisco Sánchez Girón(a) Paquillo y Ana Gutiérrez Rodríguez (a) Tangerina. ACGG. 


\section{La descolonización del Norte de África en perspectiva histórica *}

* Informe presentado al $17 .{ }^{\circ}$ Congreso Internacional de Ciencias Históricas. Madrid, 28 de agosto -2 de septiembre, 1990. 